\title{
MONITORAMENTO DAS CONTENÇÕES UTILIZADAS NAS ENCOSTAS DA BA-099 (PERÍODO DE 2011 A 2016), ENTRE SUBAÚMA E IMBASSAI, LITORAL NORTE DA BAHIA
}

\author{
Jornis Vilas Boas Santos'; Carlos César Uchôa de Lima²; Ailana da Silva Mendes ${ }^{3}$ \\ 1. Bolsista PIBIC/FAPESB, Graduando em Engenharia Civil, Universidade Estadual de Feira de Santana, e-mail: \\ jorn_is@hotmail.com \\ 2. Orientador, Departamento de Exatas, Universidade Estadual de Feira de Santana, e-mail: uchoamaster@gmail.com \\ 3. Participante do projeto, Departamento de Tecnologia, Universidade Estadual de Feira de Santana, e-mail: \\ ailanamendes@hotmail.com
}

PALAVRAS-CHAVE: Monitoramento; Contenção de Encostas; Movimento de Massa.

\section{INTRODUÇÃO}

Movimentos de massa vêm sendo discutidos na atualidade, pois, além de serem agentes da evolução da paisagem, trazem também, implicações para cidades topograficamente acidentadas e para as margens de diversas rodovias (Santos, 2016). Uma das causas mais comuns no desencadeamento de movimento de massas seria a modificação geométrica da massa terrosa ou rochosa (Guidicine e Nible, 1984), com a implantação de taludes, que facilitam a implantação de ruas e estradas. Esses cortes de estrada podem atingir zonas de fraqueza que podem ter suas origens ligadas à origem do material rochoso e ou sedimentar, ou oriundos da ação do neotectonismo como, juntas, falhas e sismitos (COELHO \& LIMA 2006, DANTAS \& LIMA 2008, LIMA et al 2008, LIMA, 2010).

Para que os cortes de estrada mantenham a sua estabilidade esperada e não provocar acidentes, é necessário a execução de obras de contenção, que devem ser escolhidas, de acordo com a dimensão, os materiais constituintes e as zonas de fragilidades da encosta (Santos, 2016). Contenção é todo elemento ou estrutura destinado a contrapor-se a empuxos ou tensões geradas em um maciço cuja condição de equilíbrio foi alterada por algum tipo de escavação, corte ou aterro (Ranzini, 1998).

Esta pesquisa foi executada ao longo da BA-099, entre as cidades de Subaúma e Imbassai (Figura 1). Foi possível realizar o monitoramento dos tipos de contenções ao longo da área estudada, comparando com os resultados encontrados oriundos dessa pesquisa a partir do ano de 2011. Para tanto, etapas de campo se fez necessário, com o intuito de reavaliar as contenções de encostas, quanto aos seus parâmetros físicos, e assim descrever e caracterizar os parâmetros adotados nesse período de cinco anos além de analisar a adequabilidade das mesmas. 


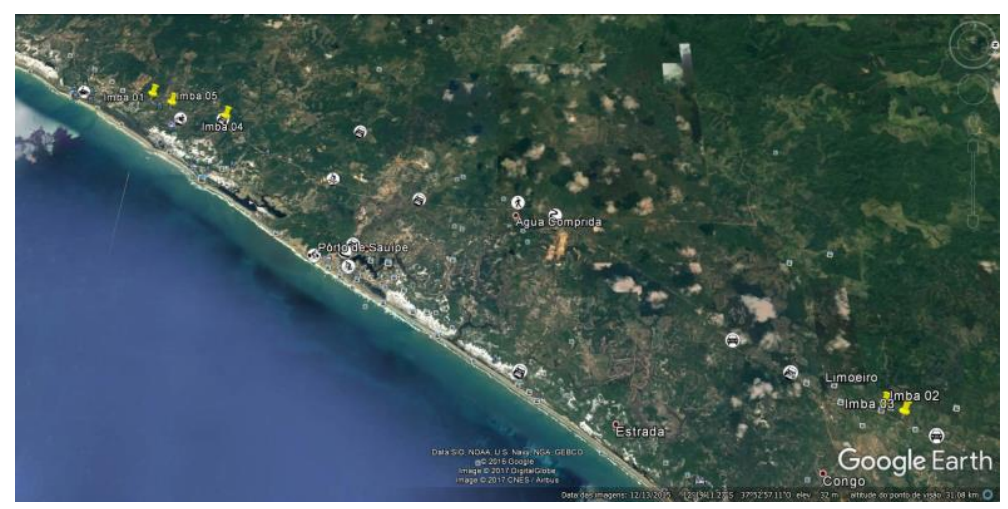

Figura 1: Área de estudo. Fonte: Google Earth (2017).

\section{MATERIAL E MÉTODOS}

Durante todo o período foram feitos levantamentos bibliográficos em livros e artigos que abordassem a área da Geotecnia.

Estudos de campo foram realizados com a finalidade de identificar, caracterizar e descrever os diversos tipos de contenções utilizadas. Para esta etapa foi necessário à utilização de alguns instrumentos tais como bússola, GPS, câmera fotográfica e trena. A bússola foi utilizada para analisar os planos de fraqueza e o ângulo de inclinação das encostas. As coordenadas UTM foram obtidas através do GPS e os recuos e a largura dos taludes foram mensurados através da trena. Para o registro dos tipos de contenção observados nos taludes, foi utilizada a câmera fotográfica.

Os dados levantados em campo foram trabalhados para gerar as informações necessárias, visando alcançar os resultados previstos.

Foram estudados e registrados em fotografia 5 (cinco) encostas, sendo que 2 (duas) delas foram escolhidas para serem analisadas e descritas em detalhe, levando-se em consideração os tipos de contenção utilizados e os níveis de alteração e/ou preservação dos taludes.

\section{RESULTADOS E DISCUSSÃO}

De acordo com Santos (2016), as contenções existentes entre o trecho que corresponde Conde a Subaúma, sofreram algum tipo de modificação a fim de que a mesma pudesse atender as alterações das encostas ao longo do tempo devido a movimentos de massa e erosão, buscando assim, satisfazer as novas necessidades das encostas. Para o trecho em estudo (Subaúma a Imbassaí), há evidências de pouca ou nenhuma intervenção nestes últimos 5 anos, atrelado a altos índices de erosão e pequenos movimentos de massa.

Para este trecho foram estudados cinco pontos, sendo escolhidos dois deles para serem analisados e descritos em detalhe, levando-se em consideração os tipos de contenções utilizadas e os níveis de alteração e/ou preservação dos taludes.

O primeiro afloramento (Figura 2) possui coordenadas UTM 24L 0256658; 8583106 foi possível identificar que para este afloramento, o nível de manutenção nestes cinco anos não foi suficiente para barrar a grande erosão presente nesta encosta. A única contenção encontrada, foram sacos de solo cimento, que já se encontram em estado de degradação, o que evidência que nestes cinco anos, há ausência ou pouca manutenção. Também para esta encosta foi possível identificar canaletas totalmente destruídas, impedindo a drenagem superficial das águas pluviais. A ausência destas canaletas abrem espaços para a formação de ravinas, que ao passar do tempo tornam-se grandes voçorocas. Para esta encosta faz-se necessário um estudo de drenagem superficial a exemplo das canaletas, e a utilização de 
drenos profundos, que segundo Massad (2003) a utilização desses drenos profundos, tem o intuito de abaixar o nível freático, reduzindo assim, as pressões neutras e, consequentemente, aumentar a estabilidade do talude.

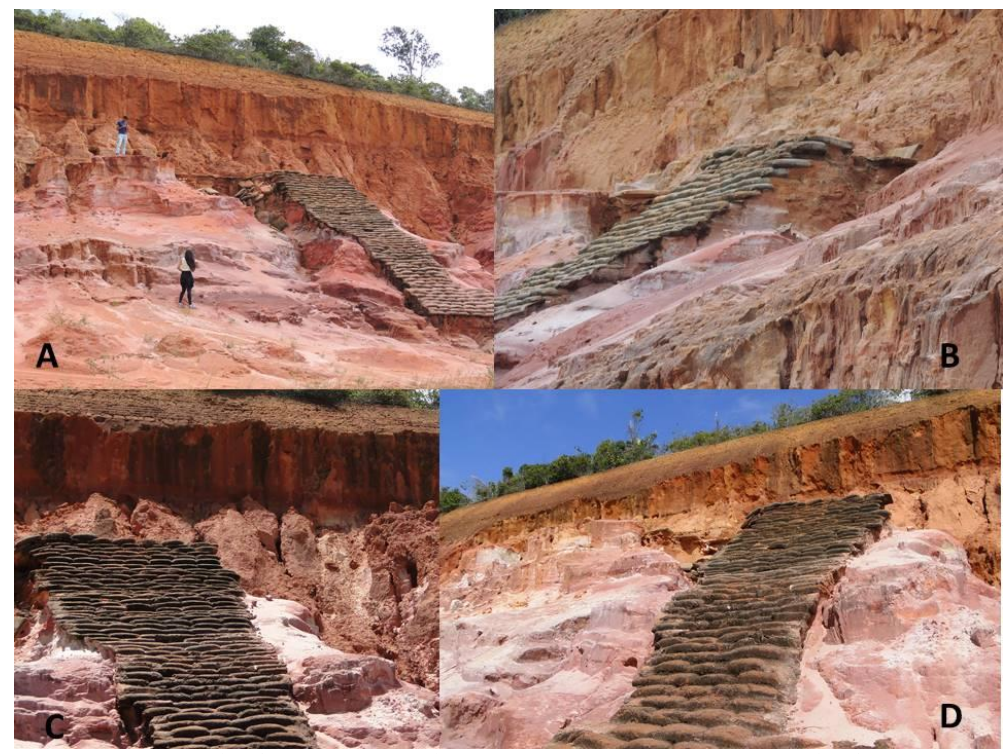

Figura 2: A, B- Contenção sacos solo cimento no ano de 2016. C, D- Contenção sacos solo cimento no ano de 2011. Fonte: Modificado do autor (2017).

O segundo afloramento (Figura 3), possui coordenadas UTM 24L 0628494; 8652448, nesta encosta a única contenção presente são sacos de solo cimento, que por sua vez se encontra em péssimo estado de conservação e manutenção. É possível ver indícios de desmoronamentos desses sacos de solo cimento e acumulo de material erodido em sua base. Nesta encosta não foi identificado à presença de canaletas, o que acarreta ainda mais o nível de erosão. Provavelmente a estabilidade desta encosta esteja ligada a constituição de seus sedimentos de origem ferruginosa, onde essas capas ferruginosas tornam a encosta mais estável, atuando como agente cimentante dificultando o desprendimento desses grãos.

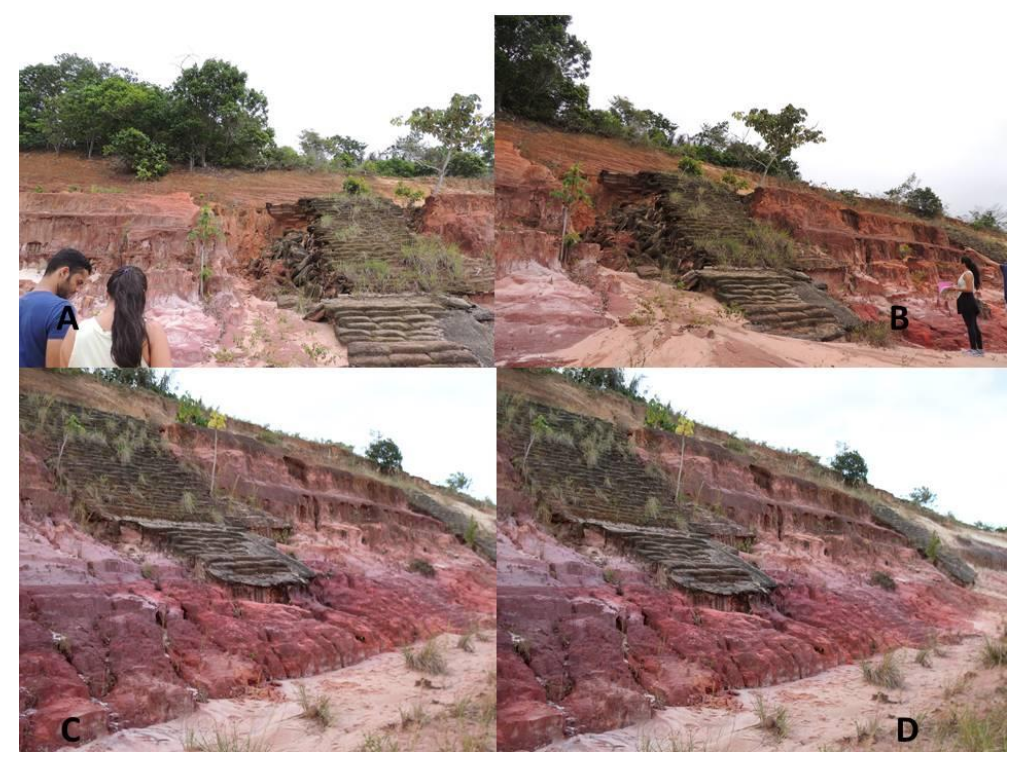

Figura 3: A, B- Contenção sacos solo cimento no ano de 2016. C, D- Contenção sacos solo cimento no ano de 2011. Fonte: Modificado do autor (2017). 


\section{CONSIDERAÇÕES FINAIS}

Ao analisar os resultados encontrados nesta pesquisa, foi possível destacar um grande poder erosivo da região associados a altos índices pluviométricos e como fator agravante, contenções com pouca manutenção. Há uma necessidade de contenções adequadas e manutenções periódicas, com o intuito de manter a estabilidade das encostas.

Nos dois afloramentos, foi possível perceber que há pouca manutenção nas contenções existentes e em alguns trechos as contenções presentes não são suficientes para barrar a expansão de grandes processos erosivos, gerando os movimentos de massa, sendo desencadeados também por falta de sistemas de drenagem que possibilitam o escoamento das aguas pluviais. A ausência dessas contenções gera preocupações com as juntas neotectônicas, que serve de conduto para o escoamento da água da chuva, gerando o processo de ravinamento (LIMA 2010). Ao decorrer do tempo essas ravinas aumentam a sua dimensão tornando-se grandes voçorocas, podendo destruir qualquer estrutura de contenção presente (Santos, 2016).

Em algumas encostas com ausência de contenção, foi possível observar que em sua maioria as que não apresentaram contenções possuíam em sua composição grandes quantidades de agentes cimentantes, como o óxido de ferro. A presença de agentes cimentantes em uma encosta não garante que a mesma vá permanecer estável, ainda mais, em encostas de escavação que possui toda sua geometria alterada. Por isso, a construção e a manutenção adequada de contenções são essenciais para assegurar que a encosta não apresente risco de erosão e eventuais movimentos de massa.

\section{REFERÊNCIAS}

COELHO, M.G.A. \& LIMA, C.C.U. Análise tectônica preliminar do Grupo Barreiras no litoral norte do Estado de Sergipe. In: Simpósio Nacional de Geomorfologia, 6, Goiânia 7p. 2006.

DANTAS, J.J..R.; LIMA, C.C.U.. As juntas tectônicas e a evolução das encostas no extremo norte do litoral da Bahia. In: VI SINAGEO/II Encontro Latino Americano de Geomorfologia, 2008, Belo Horizonte, p.1-8.

GUIDICINI, G.; NIEBLE, C. M. Estabilidade de Taludes Naturais e de Escavação. Edgar Blücher. São Paulo, 1984.

LIMA, C. C. U. Evidências da Ação Tectônica nos Sedimentos da Formação Barreiras Presentes no Litoral de Sergipe e ao norte da Bahia. Revista de Geografia. Recife: UFPE DCG/NAPA, v. especial VIII SINAGEO, n. 1, Set. 2010.

LIMA, C.C.U.; DANTAS, J.J.R.;COELHO, M.G.A. Fragilidades Tectônicas nas Encostas das Rodovias Litorâneas de Sergipe e Extremo Norte da Bahia. In: CONGRESSO BRASILEIRO DE GEOLOGIA DE ENGENHARIA, Porto de Galinhas- PE, 2008

Massad, Faiçal. Obras de Terra: Curso Básico de Geotecnia. 1.ed. São Paulo: Oficinas de Textos, 2003.

RANZINI, S.M.T. et al. Fundações: Teoria e Prática. São Paulo: PINI, 1998.

SANTOS, J. V. B; LIMA, C. C. U; MENDES, A. S; OLIVEIRA, T. S. A. CARACTERIZAÇÃO DAS CONTENÇÕES UTILIZADAS NAS ENCOSTAS DA BA-099, ENTRE CONDE E SUBAÚMA. Anais do XXI Seminário de Iniciação científica da Universidade Estadual de Feira de Santana. FEIRA DE SANTANA, BA. 2016. 